Ordynskyi Iu. M., Denefil O. V. Mechanisms for providing different reactivity to immobilization stress in male and female rats with different resistance to acute hypoxic hypoxia. Journal of Education, Health and Sport. 2020;10(4):234-242. eISSN 2391-8306. DOI http://dx.doi.org/10.12775/JEHS.2020.10.04.026

https://apcz.umk.pl/czasopisma/index.php/JEHS/article/view/JEHS.2020.10.04.026

https://zenodo.org/record/3856480

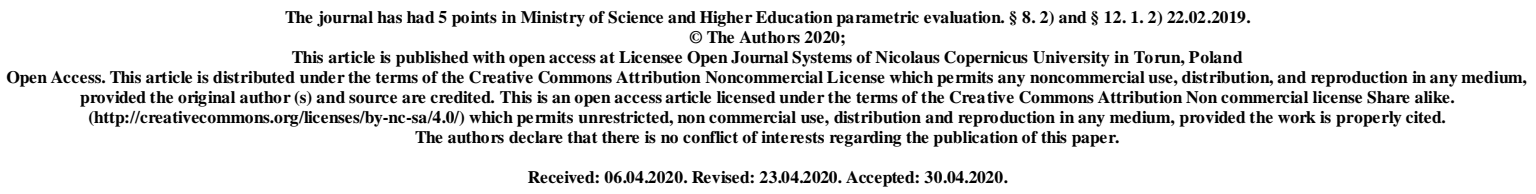

Received: 06.04.2020. Revised: 23.04.2020. Accepted: 30.04.2020.

\title{
MECHANISMS FOR PROVIDING DIFFERENT REACTIVITY TO IMMOBILIZATION STRESS IN MALE AND FEMALE RATS WITH DIFFERENT RESISTANCE TO ACUTE HYPOXIC HYPOXIA
}

\author{
Iu. M. Ordynskyi, O. V. Denefil \\ Ternopil National Medical University named by I.Ya. Horbachevskyi \\ Ministry of Health of Ukraine
}

\begin{abstract}
Attention of scientists of the world are study the features of increased resistance to hypoxia and chronic stress.

The aim of the study was to trace the features of multidirectional correlations in the mechanisms of heart damage in high- and low-resistance to hypoxic hypoxia rats (HR, LR) in different models of immobilization stress.

Material and methods of investigation. The experiments were performed on 144 outbred HR and LR aged 5.5-6 months, dividing into 3 groups - control and 2 with different model of immobilizing stress. Determine correlation between superoxide dismutase activity (SOD), catalase, GSH, glutathione peroxidase (GP), glutathione reductase (GR), conjugates diene and triene (DC, TC), Schiff bases (SB), TBA-active products, nitrite anion, in the blood - peroxidase activity $(\mathrm{PAB})$, ceruloplasmin $(\mathrm{CP})$, circulating immune complexes (CIC), oxidative modification of proteins.

Results. In HR males rats in repeated every 24 hours stress, with increasing oxidative stress, has the positive correlation with the activity of antioxidant enzymes (SOD, catalase, $\mathrm{CP}$ ), and in LR with the accumulation of CIC increases GSH. At the stress repeated every 72 hours, various mechanisms of adaptation are noted: in HR animals due to activation of
\end{abstract}


catalase and SOD, in LR - mainly due to catalase and CP. In HR rats-female with stress, which is repeated every 24 hours, adaptation occurs due to activation of SOD and PAB, in LR with the accumulation of CIC - due to PAB and GR. When the stress is repeated every 72 hours, catalase and GH are mainly activated in HR female, in LR - SOD, PAB, CP.

Conclusion. The experiments revealed significant correlations that indicate the individual characteristics of the adaptation of rats to immobilization stress, which depend on resistance to hypoxia and sex.

Key wards: correlation; oxidative stress; immobilizing stress; resistence to hypoxia; sex; rats

Introduction. Recently, more and more attention of scientists of the world are study the features of increased resistance to hypoxic hypoxia $[1,2,3,4]$. It is characteristic both for diseases of the respiratory system and in the development of altitude sickness. The pathogenesis and sanogenesis in both cases are the same. It is known that females are more resistant to hypoxia $[5,6,7]$. In the bases of all diseases is lying hypoxia. Also, both healthy individuals and patients have long been in a state of limited physical activity. Under conditions of stress, oxidative stress, depletion of antioxidants, dysfunction and structure of vital organs, including the cardiovascular system, develop. To model such a clinical situation in the experiment, it is advisable to study the mechanisms of increased resistance of persons of different sexes under different models of immobilization stress.

The aim of the study was to trace the features of multidirectional correlations in the mechanisms of heart damage in high- and low-resistance to hypoxic hypoxia rats in different models of immobilization stress.

Material and methods of investigation. The experiments were performed on 144 outbred high- and low-resistance to hypoxia rats (HR, LR) aged 5.5-6 months. Animals were divided into three groups - control and two experimental (who underwent different modes of immobilization stress). Each group had 12 males and 12 females. Isolation from the general cohort of animals with different resistance to hypoxia was performed according to the method of Berezovsky V. Ya. (1978) [8]. Stress was simulated 4 times by one-hour immobilization of rats on the back down with an interval of 24 hours between immobilization episodes (stress 1 ) and 72 hours (stress 2) [9]. All animals kept in one room on a standard diet and vivarium regime.

All experiments were performed in the morning in a specially designated room at a temperature of $18-22{ }^{\circ} \mathrm{C}$, a relative humidity of $40-60 \%$ and an illumination of 250 lux. The 
experiments were performed in compliance with the norms of the Council of Europe Convention on the Protection of Vertebrate Animals Used for Research and Other Scientific Purposes (Strasbourg, 18.03.1986), the resolution of the First National Congress on Bioethics (Kyiv, 2001) and the Ministry of Health of Ukraine № 690 of 23.09.2009 p.

Euthanasia of rats was performed by total bloodletting from the heart after previous thiopental-sodium anesthesia (60 mg/kg of body weight intraperitoneally). For further experimental study in the homogenate of the heart determined the activity of superoxide dismutase (SOD) [10], catalase [11], reduced glutathione (GSH) [12], glutathione peroxidase (GP), glutathione reductase (GR) [13], the concentration of diene, triene conjugates (DC, TC), Schiff bases (SB) [14], TBA-active products (TBA-ap) [15], nitrite anion [16], in the blood peroxidase activity (PAB) [17], ceruloplasmin (CP) [18], circulating immune complexes (CIC) [19], also oxidative modification of proteins (OMP) [20].

Statistical processing of digital data was performed using the program "STATISTICA" 6.0 ("Statsoft", USA). Correlations between independent quantitative values were determined by Pearson's correlation test (r). For the analysis, only reliable relationships between indicators were taken into account.

Results and discussion. The experiments showed a simultaneous increase in the heart and blood serum products of oxidative modification of proteins, lipid peroxidation, nitrite anion, CIC and antioxidant system indexes.

In HR-males who underwent stress 1, positive correlation were found between $\mathrm{OMP}_{370}$ and $\mathrm{CP}-\mathrm{r}=0.86$; between $\mathrm{OMP}_{370}$ and $\mathrm{GSH}-\mathrm{r}=0.77$; between $\mathrm{OMP}_{430}$ and SOD $r=0.74$; between $\mathrm{OMP}_{430}$ and catalase $-r=0.87$; between the nitrite anion and the $\mathrm{CP}-\mathrm{r}=0.90$; between the CIC and SOD $-r=0.89$; between CIC and catalase $-r=0.76$; between TBA-active products (TBA-ap) and $\mathrm{CP}-\mathrm{r}=0.85$.

Negative correlations were found between $\mathrm{OMP}_{370}$ and SOD - r=-0.99; between $\mathrm{OMP}_{430}$ and $\mathrm{CP}-\mathrm{r}=-0.94$; between $\mathrm{OMP}_{430}$ and $\mathrm{GSH}-\mathrm{r}=-0.70$; between the nitrite anion and $\mathrm{PAB}-\mathrm{r}=-0.71$; between the nitrite anion and catalase $-\mathrm{r}=-0.89$; between TBA-ap and catalase $-\mathrm{r}=-0.95$ ); between TBA-ap and PAB $-\mathrm{r}=-0.95$; between DC and catalase $-\mathrm{r}=-0.72$; between the $\mathrm{CIC}$ and the $\mathrm{CP}-\mathrm{r}=-0.95$; between $\mathrm{CIC}$ and $\mathrm{GSH}-\mathrm{r}=-0.73$.

In LR males, who underwent stress 1 , there were only three strong statistically significant correlations: between CIC and SOD $-r=-0.71$; between TBA-ap and CP $-r=-0,82$; between the CIC and GR $-r=0.87$.

In males with different resistance to hypoxia, oppositely directed compensatory and adaptive mechanisms that counteract stress damage were observed. First, in HR animals, 
compared to LR, strong reliable connections prevail in providing adaptive mechanisms and connections with unreliable values are practically absent. Secondly, in LR males with the increase of prooxidants, which indicate tissue damage, for the most part the content of antioxidants decreases, and in HR males the picture is the opposite - antioxidants often increase.

The following strong statistically significant correlations were found in males under stress 2. In HR males, positive correlation were found between TBA-ap and PAB $-r=0.85$; between DC and catalase $-r=0.86$; between DC and GP $-r=0.78$; between TC and catalase $\mathrm{r}=0.90$; between TC and GP $-\mathrm{r}=0.83$; between SB and catalase $-\mathrm{r}=0.90$; between SB and GP - r=0,85; between $\mathrm{OMP}_{370}$ and GSH $-\mathrm{r}=0.99$; between the nitrite anion and SOD $-r=0.96$; between the nitrite anion and $\mathrm{PAB}-\mathrm{r}=0.81$; between CIC and catalase $-r=0.77$; between the $\mathrm{CIC}$ and $\mathrm{GP}-\mathrm{r}=0.82$.

Negative correlations were established between TBA-ap and GSH $-r=-0.80$; between DC and SOD $-r=-0.72$; between TC and SOD $-r=-0.76$; between SB and SOD $-r=-0.86$; between $\mathrm{OMP}_{370}$ and $\mathrm{PAB}-\mathrm{r}=-0.99$; between the nitrite anion and $\mathrm{GSH}-\mathrm{r}=-0.81$; between $\mathrm{CIC}$ and $\mathrm{SOD}-\mathrm{r}=-0.82, \mathrm{CIC}$ and $\mathrm{CP}-\mathrm{r}=-0.73$.

The following strong statistically significant correlations were found in LR males under stress 2. Positive relationships were found between TBA-ap and SOD - r=0.77; between TBA-ap and GR - r=0.99; between the nitrite anion and catalase $-r=0.87$. Negative correlations were found between TBA-ap and catalase $-r=-0.75$; between DC and CP $\mathrm{r}=-0.97$; between $\mathrm{TC}$ and $\mathrm{CP}-\mathrm{r}=-0.97$; between $\mathrm{OMP}_{370}$ and $\mathrm{CP}-\mathrm{r}=-0.73$; between the nitrite anion and SOD $-\mathrm{r}=-0.91$; between the nitrite anion and $\mathrm{GR}-\mathrm{r}=-0.94$.

In males with different resistance to hypoxia, there are different relationships between the content of nitrite anion and SOD, which indicates the protective effect of the antioxidant in HR, and a decrease in its protective mechanism in LR (Fig. 1, 2).

In all females who underwent stress 1 , the number of strong statistically significant correlations increased. In HR female, positive relationships were found between TBA-ap and SOD $-r=0.97$; between TBA-ap and catalase $-r=0.94$; between TBA-ap and GP $-r=0,89$; between TBA-ap and GR - r=0.97; between SB and PAB - r=0,79; between $\mathrm{OMP}_{370}$ and $\mathrm{PAB}-\mathrm{r}=0.80$; between $\mathrm{OMP}_{430}$ and catalase $-\mathrm{r}=0.81$; between the CIC and SOD $-\mathrm{r}=0.97$; between CIC and catalase $-r=0.96$; CIC and GP $-r=0.95$; CIC and GR $-r=0.99$. 


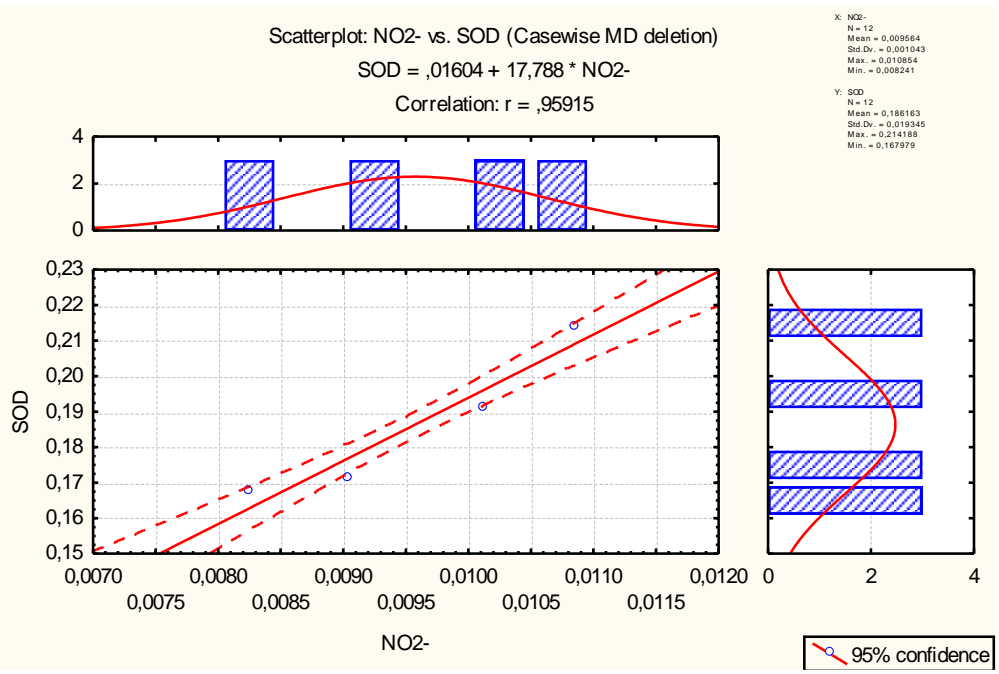

Figure 1 - Correlation relationships in male HR between superoxide dismutase activity and nitrite anion content under stress 2

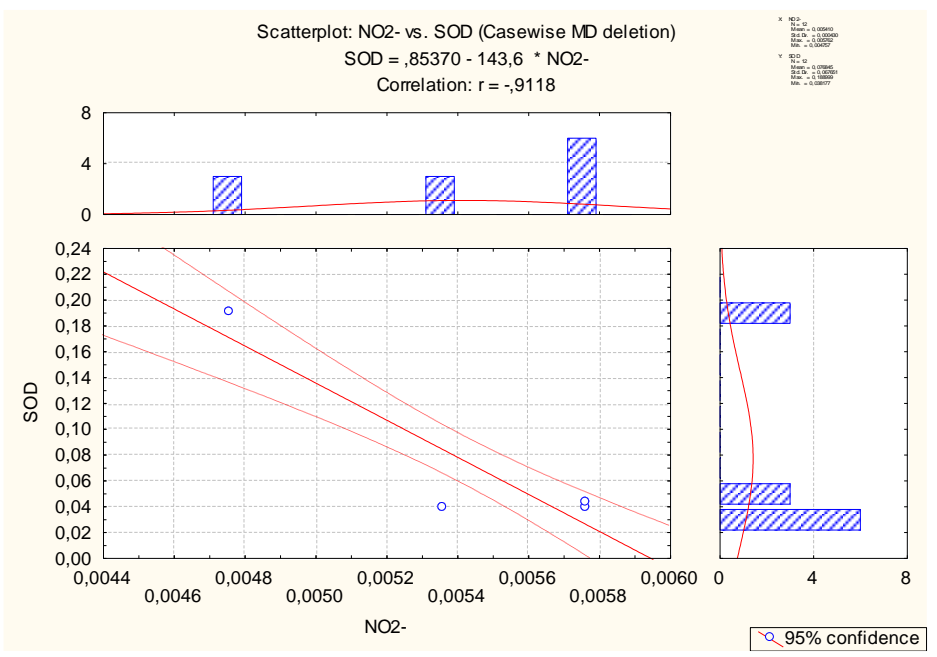

Figure 2 - Correlation relationships in male LR between superoxide dismutase activity and nitrite anion content under stress 2

Negative correlations were found between DC and SOD - r=-0.92; between DC and catalase $-\mathrm{r}=-0.93$; between DC and GP $-\mathrm{r}=-0.96$; between DC and GR $-\mathrm{r}=-0.97$; between TC and catalase $-r=-0.79$; between $\mathrm{SB}$ and $\mathrm{CP}-\mathrm{r}=-0.80$; between $\mathrm{SB}$ and $\mathrm{GSH}-\mathrm{r}=-0.94$; between $\mathrm{OMP}_{370}$ and SOD $-\mathrm{r}=-0.88$; between $\mathrm{OMP}_{370}$ and catalase $-\mathrm{r}=-0.88$; between $\mathrm{OMP}_{370}$ and $\mathrm{CP}-\mathrm{r}=-0.77$; between $\mathrm{OMP}_{370}$ and $\mathrm{SOD}-\mathrm{r}=-0.75$; between $\mathrm{OMP}_{370}$ and $\mathrm{GR}-$ $\mathrm{r}=-0.87$; between the nitrite anion and SOD $-\mathrm{r}=-0.95$; between the nitrite anion and catalase $\mathrm{r}=-0.94$; between the nitrite anion and GP $-\mathrm{r}=-0.85$; between the nitrite anion and GR $\mathrm{r}=-0.95$. 
In LR females, positive relationships were found between the CIC and SOD $-\mathrm{r}=0.86$; between CIC and catalase $-r=0.97$; CIC and PAB $-r=0.99$; CIC and GP $-r=0.97$. Negative correlations were found between DC and SOD $-r=-0.85$; between DC and catalase $-r=-0.98$; between DC and PAB - r=-0.94; between DC and GP $-r=-0.95$; between TC and SOD $\mathrm{r}=-0.85$; between TC and catalase $-\mathrm{r}=-0.96$; between $\mathrm{TC}$ and $\mathrm{PAB}-\mathrm{r}=-0.92$; between $\mathrm{DC}$ and GP $-\mathrm{r}=-0.95$; between the nitrite anion and SOD $-\mathrm{r}=-0.87$; between the nitrite anion and catalase $-r=-0.97$; between the nitrite anion and $\mathrm{PAB}-\mathrm{r}=-0.94$; between the nitrite anion and $\mathrm{GP}-\mathrm{r}=-0.91$.

Thus, correlations were found that indicate the sexual characteristics of the response of rats with different resistance to hypoxia to immobilization stress. The severity of the reaction is the same in females, and differs significantly in males. At stress at females growth of antioxidants in HR and decrease in antioxidants in LR is only noted at increase in TBA-ap.

The following strong statistically significant correlations were found in HR females under stress 2. Positive relationships were found between DC and GSH $-\mathrm{r}=0.85$; between TC and $\mathrm{CP}-\mathrm{r}=0.84$; between $\mathrm{SB}$ and $\mathrm{CP}-\mathrm{r}=0.99$; between $\mathrm{SB}$ and $\mathrm{GP}-\mathrm{r}=0,71$; between $\mathrm{OMP}_{370}$ and catalase $-\mathrm{r}=0.75$; between $\mathrm{OMP}_{370}$ and $\mathrm{GSH}-\mathrm{r}=0.94$; between the nitrite anion and catalase $-r=0.97$; between the nitrite anion and GSH $-r=0.77$; between CIC and catalase $-r=0.92$; between the CIC and GR $-r=0.77$.

Negative correlations in female HR were found between TBA-ap and SOD - r=-0.99; between TBA-ap and GP $-r=-0.72$; between TBA-ap and GR $-r=-0.79$; between DC and $\mathrm{PAB}-\mathrm{r}=-0.77$; between $\mathrm{OMP}_{370}$ and $\mathrm{PAB}-\mathrm{r}=-0.99$; between $\mathrm{OMP}_{430}$ and $\mathrm{CPU}-\mathrm{r}=-0.85$; between the nitrite anion and $\mathrm{PAB}-\mathrm{r}=-0.90$.

The following strong statistically significant correlations were found in LR females under stress 2. Positive relationships were found between TBA-ap and $\mathrm{CP}-\mathrm{r}=0.93$; between TC and SOD $-r=0.99$; between TC and GP $-r=0.80$; between TC and GR $-r=0.79$; between SB and SOD - r=0,81; between SB and catalase - r=0.99; between $\mathrm{OMP}_{370}$ and SOD $\mathrm{r}=0.71$; between $\mathrm{OMP}_{370}$ and catalase $-\mathrm{r}=0.76$; between $\mathrm{OMP}_{430}$ and $\mathrm{CP}-\mathrm{r}=0.92$; between the nitrite anion and the $\mathrm{CP}-\mathrm{r}=1.00$; between CIC and catalase $-\mathrm{r}=0.85$, between CIC and $\mathrm{PAB}-\mathrm{r}=0.74$.

Negative correlations in NG females were found between TBA-ap and catalase $\mathrm{r}=-0.84$; between TBA-ap and PAB $-\mathrm{r}=-0.90$; between $\mathrm{SB}$ and $\mathrm{CP}-\mathrm{r}=-0.87$; between $\mathrm{OMP}_{430}$ and catalase $-\mathrm{r}=-0.99$; between $\mathrm{OMP}_{430}$ and $\mathrm{PAB}-\mathrm{r}=-0.85$; between the nitrite anion and catalase $-\mathrm{r}=-0.86$; between the nitrite anion and $\mathrm{PAB}-\mathrm{r}=-0.70$; between the nitrite anion and GR $-r=-0.73$; between the CIC and the $\mathrm{CP}-\mathrm{r}=-0.99$. 
The obtained data indicate an increase in catalase and GSH with an increase in oxidative stress products (LPO, OMP, $\mathrm{NO}_{2-}, \mathrm{CIC}$ ) in $\mathrm{HR}$ female. In LR females selective antioxidant protection is noted: at increase of $\mathrm{OMP}_{370} \mathrm{SOD}$, catalase, $\mathrm{PAB}, \mathrm{GSH}$ have values; with increasing $\mathrm{OMP}_{430}$ and $\mathrm{NO}_{2-}-\mathrm{CP}$; with the growth of TBA-ap - CP and GSH; with increasing CIC - SOD, catalase, PAB.

Conclusion. The experiments revealed significant correlations that indicate the individual characteristics of the adaptation of rats to immobilization stress, which depend on resistance to hypoxia and sex. Thus, in highly resistant to hypoxia males in repeated every 24 hours stress, with increasing oxidative stress, has the positive correlation with the activity of antioxidant enzymes (SOD, catalase, ceruloplasmin), and in low resistance rats with the accumulation of CIC increases GSH, which may indicate greater adaptation of HR animals. At the stress repeated every 72 hours, various mechanisms of adaptation are noted: in HR animals due to activation of catalase and SOD, in LR - mainly due to catalase and CP. In HR rats-female with stress, which is repeated every 24 hours, adaptation occurs due to activation of SOD and PAB, in LR with the accumulation of CIC - due to PAB and GR, ie adaptation is better in HR females. When the stress is repeated every 72 hours, catalase and GH are mainly activated in HR female, in LR - SOD, PAB, CP, ie bigger mechanisms of adaptation are required to $L R$ rats female.

\section{References}

1. Altitude Omics: The Integrative Physiology of Human Acclimatization to Hypobaric Hypoxia and Its Retention upon Reascent / A. W. Subudhi, N. Bourdillon, J. Bucher [et al.] // PLoS One. 2014;9(3):e92191.

2. Gibson O. R., Taylor L., Watt P. W., Maxwell N. S. Cross-Adaptation: Heat and Cold Adaptation to Improve Physiological and Cellular Responses to Hypoxia // Sports Med. 2017;47(9):1751-1768.

3. Glutamate receptors in the nucleus tractus solitarius contribute to ventilatory acclimatization to hypoxia in rat / M. E. Pamenter, J. A. Carr, A. Go [et al.] // J. Physiol. 2014;592(Pt 8):1839-1856.

4. Colleen G. Julian, Lorna G. Moore Human Genetic Adaptation to High Altitude: Evidence from the Andes // Genes (Basel). 2019;10(2):150.

5. Shimoda L. A. Let's Talk about Sex: A Novel Mechanism by Which Estrogen Receptor $\beta$ Limits Hypoxia-Inducible Factor Expression in Pulmonary Endothelial Cells // Am. J. Respir. Cell Mol. Biol. 2018;59(1):11-12. 
6. Miller A. J., Cui J., Luck J. C., Sinoway L. I., Muller M. D. Age and sex differences in sympathetic and hemodynamic responses to hypoxia and cold pressor test // Physiol. Rep. 2019;7(2):e13988.

7. Souza G.M.P.R., Amorim M.R., Moraes D.J.A., Machado B.H. Sex differences in the respiratory-sympathetic coupling in rats exposed to chronic intermittent hypoxia // Respir. Physiol. Neurobiol. 2018;256:109-118.

8. Berezovskij V.A. Hypoxia and individual peculiarities of reactivity. - K.: Scientific thought, 1978;2-216. [in Russian]

9. Kulynskyi V.Y. \& Olkhovskyi Y.A. Two adaptation strategies in adverse conditions: resistant and tolerant. The role of hormones and receptors. Advances of modern biology. 1992;112;697-711 [in Russian].

10. Chevary S., Chaba Y., Sokei Y. The role of superoxide dismutase in the oxidative processes of the cell and the method for its determination in biological materials // Laboratory work. 1985;11:678-681 [in Russian].

11. Koroliuk M. A., Yvanova L. Y., Maiorova Y.H., Tokarev V.E. Method for determination of catalase activity // Laboratory work. 1988;1:16-19 [in Russian].

12. Moffat J. A., Armstrong P. W., Marks G. S. Investigations into the role of sulfhydryl groups in the mechanism of action of the nitrates // Canadian Journal of Physiology and Pharmacology. 1982;10(60):1261-1266.

13. Kruhlikova H. O., Shtutman I. M. Glutathionperoxidase and glutathionreductase activity of rats liver after the introduction of selenite of sodium // Ukrainian Biochemical Journal. 1976;2:227-233. [in Ukrainian]

14. Gavrilov V. B., Mishkorudnaya M. I. Spectrophotometric determination of the content of lipid hydroperoxides in blood plasma // Laboratory work. 1983;3:33-35. [in Russian]

15. Korobeinikov E. N. Modification of the determination of lipid peroxidation products in the reaction with thiobarbituric acid // Laboratory work. 1989;7:8-10. [in Russian]

16. Changes in concentration of $\mathrm{NO}_{2^{-}}$in biological fluids in diseases of gastric cancer / O. Ya. Sclyarov, I. P. Fedorovych, V. M. Korobov [et al.] // Medical chemistry. 2004;3(6):55-57. [in Ukrainian]

17. Rakytianskyi V. M., Yefimov V. H. Peroxidase and catalase activity of blood in Holstein cattle for the effects of hydrogum and microelements // Scientific Herald of LNUWMBT named after S. Z. Gzhytsky 2010;12:250-255. [in Ukrainian]

18. Clinical and laboratory diagnostics. Normative directive legal documents. $-\mathrm{K}$. : 
MVC “Medinform”, 2003. - 856 c. [in Ukrainian]

19. Belozerov E. S., Makarov T. A. Precipitation method for the study of immune complexes in patients with viral hepatitis B. // Laboratory work. 1982;12:37-39. [in Russian]

20. Meshyshen I. F. Method for determination of oxidative modification of blood plasma proteins // Bukovinian Medical Herald. 1998; 1(2):156-158. [in Ukrainian] 